\title{
Outras alteridades: apresentação
}

\section{Alessandra Santana Soares e Barros ${ }^{1}$ Gislene Maria Barral Lima Felipe da Silva²}

\begin{abstract}
O dossiê "Outras alteridades" apresenta aos leitores artigos contendo análises acerca de representações da deficiência, em suas variadas manifestações - físicas, sensoriais ou mentais -, em obras da literatura brasileira contemporânea. Esse tipo de análise tem servido grandemente à produção de conhecimento no campo das representações sociais que, ao se debruçar sobre discursos e práticas de distintas linguagens - da publicidade, da mídia impressa, do cinema e, frequentemente, da literatura -, proporcionam perspectivas sob as quais as categorias minoritárias são retratadas.
\end{abstract}

Logo, quando propusemos que se reunissem em um volume de uma revista de estudos literários amostras de compreensões possíveis acerca das maneiras como escritores têm enxergado e refletido a cegueira, a surdez ou a síndrome de Down, por exemplo, quisemos, em alguma medida, contribuir tanto com os estudos literários quanto com as ciências sociais, no sentido que nos ensina, por exemplo, o antropólogo francês François Laplantine, que

nos apresenta a forma como ela [a antropologia] se relaciona com outras atividades humanas não propriamente científicas (como a literatura e as artes pictóricas, por exemplo) [...]. Laplantine evidencia então as similitudes entre a literatura e a etnografia: em ambas há um interesse por questões cotidianas (a que chama de o "microscópico", o "infinitamente pequeno"), uma preocupação genuína de assumir uma posição crítica em relação aos preconceitos (linguísticos e sociais na literatura, etnocêntricos na etnografia) (Freitas e Doula, 2007, p. 1.119, 1.121).

Para tanto, é preciso reconhecer que as singularidades da experiência humana podem ser alcançadas tanto na relação de troca vivida na realidade mundana, quanto na virtualidade da literatura, e ali, mesmo

\footnotetext{
${ }^{1}$ Doutora em ciências sociais, professora da Universidade Federal da Bahia (UFBA), Salvador, BA, Brasil. Dorcid.org/0000-0003-3347-6323. E-mail: alssb@ufba.br

2 Doutora em literatura, professora aposentada da Secretaria de Estado da Educação do Distrito Federal (SEDF), Brasília, DF, Brasil. (Dorcid.org/0000-0003-2037-0167. E-mail: gislenebarral@felipedasilva.com
} 
nos simulacros da ficção mais fantástica. Assim, as ciências sociais e humanas ganham mais campos empíricos quando se debruçam sobre romances, novelas, contos que nos falam sobre a condição de ser cego, de não andar ou não ouvir. Ou ainda sobre a experiência de se relacionar com a deficiência do outro próximo, em família ou no trabalho.

Mas, como não poderia deixar de ser, razão pela qual aqui se apresenta este número temático da revista, ganha também a literatura quando descobre que precisa se exercitar em diferentes estruturas narrativas para melhor alcançar as nuanças expressivas contidas na incapacidade de enxergar, na perda da audição, ou na possibilidade de recuperação desta. Os conflitos existenciais e os dilemas éticos que permeiam a experiência da perda de um sentido, como o da visão, ou a resignação por sua sempre inexistência e consequente incurabilidade, por vezes só são possíveis de serem dimensionados à custa dos arranjos linguísticos proporcionados por um bom escritor.

$\mathrm{O}$ orgulho atingido pelo nascimento do filho imperfeito, a culpa alimentada pela secreta vergonha ou a inveja dirigida àquelas famílias cujas crianças não parecem anormais são legítimas emoções de pais e mães que, assim, ressoam na literatura sob abordagem sensível, pungente e necessária. E quando se concebe a variedade de formatos discursivos da qual a literatura pode se servir para contar estórias, ainda mais potente ela se mostra em lograr-se acervo de registros da experiência humana. Se a palavra não for suficiente, a imagem que com ela dialoga nos livros ilustrados ajudará na missão de fazer entender o conjunto complexo de sentimentos vividos, no caso, então, a partir da deficiência. E se a poesia, que por vezes substitui a prosa na tarefa de imprimir sentidos cognoscíveis, se faz ainda mais peculiar - como nos poemas visuais do concretismo, do haicai ou dos gestos da língua de sinais -, que ali, portanto, debrucem-se as análises literárias merecidas.

Isso posto, resta dizer, então, que foi esse o propósito deste número temático da revista Estudos de Literatura Brasileira Contemporânea. Para apresentá-lo, optamos por trazer, na forma de breves resenhas, cada um dessas obras literárias, introduzindo-as e remetendo aos artigos que então compõem o dossiê.

Iniciamos pelo livro Um garoto chamado Rorbeto, publicado em 2005, escrito pelo rapper Gabriel, O pensador e ilustrado por Daniel Bueno, cuja força levou-o a vencer o Prêmio Jabuti de Melhor Livro Infantil em 2006. Sua potência se deve, por um lado, à construção, na literatura 
infantil, da experiência de um menino com deficiência física - tratando de uma minoria excluída sob um viés emancipatório -; por outro, ao uso de uma composição gráfica que privilegia as linguagens da sociedade contemporânea, com contornos geométricos, colagens, texturas e grafismos, bastante apreciadas e consumidas pelos jovens.

Um garoto chamado Rorbeto é analisado por Ivone Silva de Jesus no artigo "Literatura infantil e a alteridade polidáctila deixada para a próxima página", em que a autora levanta questões relacionadas à representação do corpo "diferente" e mostra que essa diferença pode abrir possibilidades de reflexão a partir dos implícitos ou explícitos desse corpo. A autora também defende a ideia de que a literatura brasileira contemporânea, ao abordar a pluralidade de sujeitos e vozes sociais marcados pelas diferenças, dá visibilidade àqueles indivíduos cujas singularidades os situam fora do padrão fixado como o "normal", mostrando, ainda, como essa diferença pode figurar como fator de exclusão. Com isso, a literatura estaria contribuindo para a manutenção ou para a desconstrução de preconceitos, estereótipos e estigmas construídos com base no estranhamento à diferença corporal.

A segunda obra em análise é Turismo para cegos, de Tércia Montenegro, que traz como protagonista Laila, uma estudante e professora de artes visuais. Ela é professora de Pierre, com quem passa a namorar. Após as primeiras aulas, Laila descobre uma retinopatia que lhe está deixando cega. À medida que vai perdendo a visão, ela também vai perdendo/mudando sua identidade. Pierre decide então viajar com Laila para lhe trazer alegria.

Turismo para cegos é objeto de estudo do artigo "Cegueira e crueldade na narrativa de Tércia Montenegro", de Milena Cláudia Magalhães Santos Guidio. Nele, a autora problematiza a perda de identidade que acompanha a perda da visão, passando o sujeito de vidente a não vidente. A elaboração da realidade ficcional pauta-se pela relação entre visível e invisível, uma vez que a narradora - uma balconista de pet shop e aspirante a escritora, que vende um falso cão-guia ao casal Pierre e Laila - alterna entre a primeira e a terceira pessoas, mostrando-se ora observadora dos fatos, ora presentificada e totalmente comprometida com o que narra. A crueldade a que o título do artigo se refere consiste na exclusão social a que os cegos são condenados com a perda da visão e, consequentemente, a perda da vida anterior; na forma como o casal se relaciona; e na própria personalidade da personagem cega. 
O mesmo romance é foco do artigo "Turismo para cegos: velhos e novos simbolismos numa obra literária sobre a cegueira", de Manoela Cristina Correia Carvalho da Silva, Alessandra Santana Soares e Barros e Miralva dos Santos Silva. As autoras apresentam exemplos de representações da figura do cego em personagens da literatura e apontam os estereótipos mais comuns presentes nas obras literárias, bem como a cosmovisão ocidental acerca do fenômeno da deficiência visual. Na sequência, o artigo se desenvolve buscando compreender como o romance de Tércia Montenegro formula a questão da deficiência visual, examinando se a obra consegue dar um salto em relação às representações cristalizadas e assentadas em preconceitos e estereótipos, ou se apenas os reproduzem. Além disso, procura entender de que modo a protagonista se relaciona com a própria cegueira e com os demais personagens videntes. As ideias de Goffman (1981) acerca do conceito de "estigma" iluminam a análise de Turismo para cegos. As autoras justificam que possíveis estereótipos em relação à cegueira presentes na obra podem ser atribuídos tanto a presença de uma narradora parcial, comprometida visceralmente com o que narra, quanto ao desejo de apresentar um repertório de representações sobre a deficiência compartilhado culturalmente em nossa sociedade e, nesse caso, reproduzido pela narradora.

Em seguida, o corpus do próximo artigo é composto pelo conto "Amor", de Clarice Lispector, e pelo romance Um crime delicado (1997), de Sérgio Sant'Anna.

"Amor" faz parte da coletânea Laços de família (1960) e traz a história da personagem Ana, que vive uma rotina tranquila e organizada, cumprindo suas funções de mãe, dona de casa e esposa. Ao encontrar um homem cego mascando chicletes na parada do bonde que a levaria para casa, Ana é levada a experimentar um novo momento de sua existência, percebendo uma ruptura que a lança para uma jornada interior - uma compreensão de si, por meio do outro. Esse momento epifânico ilumina a compreensão de Ana, provocada pelo encontro com a falta, a ausência e a deficiência representadas pelo homem cego.

Um crime delicado traz a deficiente física Inês em contato com o crítico de teatro Antônio Martins, de quem se torna vítima de um relacionamento ambíguo: ao mesmo tempo em que ele nutre por ela um fascínio obsessivo, a ponto de sua deficiência funcionar como um fetiche, um misto de piedade, afeto e perversão transformam-se em um mistério que o seduzem de uma forma contraditória. Acusado de haver estuprado 
a moça, Martins se defende recontando sua história na tentativa de incriminar seu rival, o artista plástico Vitório Brancatti. Como numa trama policial, as imagens que remetem ao crime se sobrepõem, cabendo ao leitor interpretá-las e tirar delas suas próprias conclusões.

Essas duas narrativas foram eleitas por Valter Henrique de Castro Fritsch como foco em seu artigo intitulado "A fratura da alteridade em 'Amor', de Clarice Lispector, e Um crime delicado, de Sérgio Sant'Anna". Aproximando os dois textos literários e a trajetória de seus protagonistas, o autor procura compreender a fratura da alteridade que se dá a partir do contato das personagens Antônio Martins e Ana com pessoas que possuem uma deficiência física - um homem cego e uma mulher manca, respectivamente -, observando como esse encontro com a alteridade da falta os modifica em definitivo, provocando seu conflito com a própria identidade e seu lugar no mundo. Para isso, o artigo discute o conceito de fratura, essa fratura que nasce justamente da incompletude do sujeito diante do mundo.

A surdez recebeu apreciações a partir de diferentes produções literárias: duas autobiografias e poemas em língua brasileira de sinais (Libras).

Crônicas da surdez, de Paula Pfeifer, é uma das biografias. Embora a escritora seja uma surda oralizada, cujas experiências mais significativas para a construção de sua identidade tenham sido a leitura labial e a utilização de tecnologia para amplificação do som, seus relatos dialogam bastante com outra surdez: aquela dos sinais, que não se expressa bem por escrito, que se manifesta culturalmente através da militância política e que tem dominado os espaços da mídia. Além disso, o que demarca especificamente sua narrativa é que a surdez que a constituiu como pessoa com deficiência chegou para ela aos poucos, pois ela não nasceu surda. Nesse sentido, pode-se dizer que ela foi ao mundo do silêncio, tendo lá chegado com referências, valores e juízos do mundo dos sons. No mundo do silêncio esteve por muito tempo flertando com o mundo dos sons pelos aparelhos e pelas conversas mantidas via leitura labial. E, como poucos surdos podem, escolheu onde queria ficar, tendo retornado ao mundo dos sons. Essa escolha the foi dada não apenas pelas possibilidades tecnológicas e científicas dos aparelhos e da fonoaudiologia. Foi, antes de tudo, pela possibilidade de comparar diferentes realidades fenomênicas, pois tendo passado por uma perda consciente e gradual da audição, sua percepção e sensibilidade contrastiva dos dois "mundos" é muito peculiar. Nesse tocante, as 
descrições da Paula Pfeifer são de uma qualidade literária surpreendente para uma escritora não profissional. Trata-se, portanto, de um livro para ser lido por quem se interesse pelos dilemas existenciais da surdez.

Por ocasião desse dossiê temático, Crônicas da surdez foi apreciado por Bianca Silva Lopes Costa e Sátila Souza Ribeiro, no artigo "A representação da surdez na literatura: vivências e experiências de surdos e familiares de surdos". Nesse mesmo trabalho, as autoras analisam também o livro A sonoridade da surdez, de Kátia Maria Oliveira Franco, também uma autobiografia, narrada na forma de um extenso e detalhado diário, que conta passagens da jornada de uma mãe em busca de tratamento para sua filha, nascida surda. Nesse sentido, a partir dos relatos, o diário recupera aquilo que a antropologia da saúde chama de itinerários terapêuticos, conceito segundo o qual as formas como as pessoas interpretam a doença, que por sua vez dialoga com os significados culturalmente construídos, determina o cuidado ofertado e o tipo de assistência procurada (Helman, 1984). O estilo narrativo desse livro, bastante coloquial, quase descompromissado com a norma culta da língua, talvez não aproxime leitores que apreciam a qualidade estética que a atenção aos padrões formais da escrita podem dar a uma obra. Por outro lado, na medida em que se revela um ótimo exemplo de engajamento político e psicossocial pela causa da deficiência auditiva, o livro atende às expectativas de um leitor que busque informação sobre surdez e abordagens educacionais, encontrando-as, assim, para além da frieza da literatura técnico-científica. A característica de exposição de momentos da vida privada, à custa da revelação de sentimentos e percepções muito íntimos, quase confessos, faz do livro, igualmente, um exemplo daquilo que Goffman, ao discorrer sobre a carreira moral do estigmatizado, assim descreve:

Discussões intensas sobre as posições pessoais podem ser apresentadas em forma de ficção, junto com profundas crises de consciência. São embrulhadas e colocadas à disposição fantasias de humilhação e triunfo sobre os normais. Nesse ponto, o mais privado e embaraçoso é o mais coletivo, porque os sentimentos mais profundos do indivíduo estigmatizado são feitos do mesmo material que os membros de sua categoria apresentam, numa versão escrita ou oral bastante fluente (Goffman, 1981, p. 123).

A surdez foi ainda objeto de crítica por meio da análise semiótica de poemas em Libras. As línguas de sinais são originalmente poéticas, artísticas, pois capturam a atenção do receptor para além dos significados 
que os sinais queiram imprimir. Isso porque a movimentação das mãos, a exploração do espaço, a velocidade com que os gestos se deslocam no ar compõem, por si só, uma performance cênica. Diferentemente das outras obras analisadas neste dossiê, nas quais a deficiência está localizada a partir do conteúdo da narrativa, dessa vez, nos poemas em Libras, a surdez está contida no próprio suporte expressivo: a Libras constitui o gênero textual - poema sinalizado - ele mesmo.

Nesses termos, Lodenir Becker Karnopp e Renata Heinzelmann Bosse, no artigo intitulado "Mãos que dançam e traduzem: poemas em língua brasileira de sinais", discutem as possibilidades estéticas do "poema sinalizado" a partir do potencial de seus temas. Resgatam, assim, o lugar desse recurso discursivo para exemplificar o que chamam de "experiência surda". Assim também apresentam, na perspectiva da elaboração dos gestos e dos sinais e na apreensão visual dos sentidos que lhe correspondem, os apelos da expressão poética em língua de sinais que os fariam análogos à rima presente em alguns poemas recitados oralmente.

O filho eterno, do escritor Cristóvão Tezza, é um livro sobre a ferida narcísica que se abre quando um pai se vê reproduzido na imperfeição inequívoca do filho. É, assim, um livro sobre esse filho e sua síndrome de Down, mas, ao mesmo tempo e, principalmente, um livro sobre a frustração de se saber continuado na condição defeituosa de uma deficiência. Sendo esse pai um literato, para quem a atitude intelectual é um valor civilizatório, a deficiência ter comprometido justamente a inteligência da criança faz doer ainda mais a ferida.

Para contar sua história, o autor discorre sobre a deficiência mental de uma maneira quase pura, descontaminada de muitas das assunções do discurso politicamente correto e da militância do bem. Ao mesmo tempo, o faz de modo bastante informado, tanto pelo conhecimento de causa, fruto da experiência vivida, quanto pelo conhecimento acadêmico das ciências humanas e da filosofia, nas quais ele se ampara reflexivamente. Nesse sentido, a erudição e o domínio das ferramentas literárias dão à narrativa de Tezza vigor e leveza ao mesmo tempo. É esse aspecto que favorece ao leitor a digestão das verdades cortantes e da franqueza assertiva e niilista com as quais o autor-personagem se expressa nessa sua biografia.

O filho eterno é um livro que absolve os pais de crianças com deficiência das expectativas de heroísmo que a sociedade tem deles. Nesse sentido, localiza-se, no mercado editorial, não somente como literatura de qualidade 
artística inquestionável como um antídoto à hipocrisia e à pieguice das promessas de superação de muitas obras de autoajuda que tanto se aproveitam das experiências de luto na paternidade.

A obra $O$ filho eterno está explorada em dois artigos do presente dossiê: "À procura do berço esplêndido: a trajetória de uma geração em $O$ filho eterno", de autoria de William Moreno Boenavides, e "A relação pai e filho embalada pela síndrome de Down em $O$ filho eterno e Mallko y Papá", de Mariana Cortez, Dinéia Ghizzo Neto Fellini e Rosangela Marcilio Bogoni. Como se pode ver, esse segundo trabalho apreciou igualmente outro livro.

O livro Mallko y Papá, do argentino Gusti, também retrata a relação de um pai - o próprio autor - com seu filho pequeno, que tem síndrome de Down. Discute os dramas da aceitação de um filho diferente que não correspondeu aos sonhos de paternidade e à vaidade de um artista plástico talentoso. Mais do que propriamente contar uma história, o livro apresenta passagens da vida de um pai e sua criança com deficiência, sob a mensagem subliminar que a relação dos dois se dá, na maior parte do tempo, apenas como a de um pai e um filho comuns. Do ponto de vista da forma, o livro é um álbum de colagens de fotografias e desenhos, às vezes quase rascunhos, e mesmo rabiscos da criança, que se justapõem para representar imagens do cotidiano de Mallko e seu pai. Mas não se trata de um livro ilustrado convencional, pois possui um ritmo próprio, dado pela rápida alternância das gravuras e por aspectos da diagramação que articulam diferentes planos e profundidades de uma cena, assim como ângulos do rosto do menino Malko. A respeito do potencial dessa função gráfica, Linden afirma que resulta daí um texto narrativo claro de se acompanhar e, ao mesmo tempo, com vários efeitos rítmicos ou expressivos causados pela aproximação texto/imagem - especialmente nos diálogos. [...] As diagramações sustentam diferentes funções das imagens, além de trazerem óbvia implicação rítmica à leitura (Linden, 2011, p. 154).

A leveza poética está dada também pelo traço e pela paleta do escritor/ilustrador, que captura com precisão a expressão ingênua de uma criança sob a espontaneidade de momentos banais recortados da rotina de uma família. Isso tudo proporcionou à narrativa, tanto ilustrada quanto escrita - cujo texto e palavras se valem do mesmo risco 
manuscrito - a capacidade de encantar o leitor, seduzido, então, pela incomparável qualidade estético-visual deste livro.

A síndrome de Down foi ainda objeto de análise, no decorrer deste número temático, a partir de outra obra literária: Olhos azuis coração vermelho, da escritora Jane Tutikian. É uma narrativa curta e ágil que abarca a relação da personagem principal com as crises da adolescência. Fala da novidade da menstruação, da necessidade de ser aceita e querida pelo grupo de amigos, do primeiro amor que não se sabe correspondido, dos enfrentamentos de autoridade com os adultos, do descontentamento em ter a irmã mais nova deficiente e do constrangimento de assim se sentir. Nesse sentido, a entrada da personagem com síndrome de Down na história é, a princípio, despretensiosa. E sua permanência na trama se faz situada de modo tão equilibrado em meio aos outros elementos conflitantes do amadurecimento de uma adolescente, que se torna, assim, a força diferencial da narrativa. $\mathrm{O}$ estilo discursivo da autora reproduz de modo bastante genuíno a linguagem de uma menina de 13 anos e a perspectiva de uma adolescente. Além disso, Jane Tutikian imprime personalidade à personagem, tendo o mérito de fazê-lo no curto espaço permitido por um livro infantojuvenil, cujo vocabulário não permite exceder o repertório semântico do público jovem ao qual ele se destina. Ao mesmo tempo que poupa o leitor da pregação ideológica sobre o respeito às diferenças, o livro não deixa de transmitir uma mensagem singela e tocante sobre reencontros e aceitação da diversidade. Olhos azuis coração vermelho foi, então, apreciado criticamente no artigo intitulado "Vermelho da cor do sangue, azul da cor do céu", de autoria de Juliana Santos.

Como se pode ver, os colaboradores deste número debruçaram-se sobre escritores e obras que versam sobre algum tipo de deficiência. Sempre importante lembrar que, nesse trabalho de meta-análise, houve mais que endossos: houve interpretações e releituras sempre abertas a novas compreensões, tanto quanto o foram as obras que lhes serviram de fonte de estudo.

\section{Referências}

FREITAS, Humberto Barbosa; DOULA, Sheila Maria (2007). François Laplantine. A descrição etnográfica. Fragmentos de Cultura, Goiânia, v. 17, n. 1112, p. 1119-1124. 
Outras alteridades: apresentação

GOFFMAN, Erving (1981). Estigma: notas sobre a manipulação da identidade deteriorada. Rio de Janeiro: Guanabara Koogan.

HELMAN, Cecil (1994). Cultura, saúde e doença. Porto Alegre: Artes Médicas.

LINDEN, Sophie Van der (2011). Para ler o livro ilustrado. São Paulo: Cosac Naify. 